Health Education in Practice: Journal of Research for Professional Learning

Vol. 3 | No. 1 | 2020

Research \& Evaluation article (double blind peer-review)

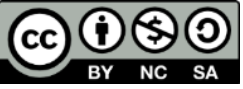

Copyright is held by the authors with the first publication rights granted to the journal. Conditions of sharing are defined by the Creative Commons License Attribution-ShareAlikeNonCommercial 4.0 International

Citation: Thawley, A, Aggar, C \& Williams, N 2020, 'The educational needs of triage nurses', Health Education in Practice: Journal of Research for Professional Learning, vol. 3, no. 1 DOI http://dx.doi.org/10.339 66/hepj.3.1.14121

\section{The educational needs of triage nurses}

\author{
Andrea Thawley ${ }^{1}$, Christina Aggar (D) ${ }^{2}$, Noelene Williams ${ }^{1}$
}

\section{ABSTRACT}

The role of triage nurses is critical to ensuring patient safety and timely access to emergency care. Continuing professional development and ongoing support is required to effectively support the competence of triage staff. To date, very few studies have sought to describe the educational needs of triage nurses.

This study aimed to identify which type of educational support nurses feel they need to manage the triage process.

A validated questionnaire was used to explore triage nurses' perceived educational support needs in relation to managing the triage process.

On average, participants had 11.33 years of experience in their current role $(S D=7.27)$, 15.43 in emergency $(S D=9.80)$ and 13.44 in triage $(S D=9.16)$. Triage nurses $(n=27)$ identified the introduction of new ideas at triage to increase efficiency as the area in which they were in greatest need of training. Priority education needs that focused on clinical tasks, such as physical assessment skills, particularly in relation to observations and vital signs, to inform triage decision making were also identified. These priority education needs will inform the design of education programs and the development of the capabilities of the nursing workforce.

Future research should seek to explore the traditional responsibilities of triage nurses, particularly to address queuing and delays at triage.

Keywords: triage, emergency, education, patient flow, Emergency Triage Education Kit.

\footnotetext{
1 The Tweed Hospital, Tweed Heads, Australia

2 Southern Cross University, Bilinga Australia
}

Corresponding author: Andrea Thawley, The Tweed Hospital, PO Box 904, Tweed Heads, NSW 2485, Australia, Andrea.Thawley@health.nsw.gov.au 


\section{INTRODUCTION}

Patient safety and timely access to care in the emergency department (ED) relies upon the experience, education and training of ED nurses, including in the area of triage. Novice ED nurses require structured education and mentorship (Hitchcock et al. 2014; Varndell, Hodge \& Fry 2019). Continuing professional development and ongoing support is required to effectively support ED nurse competence in triage processes (Holloway, Arcus \& Orsborn 2018; Hitchcock et al. 2014). Educators should regularly conduct analyses of training needs to ensure that the training being provided aligns with staff needs (Gould et al. 2004). The appropriate training of nursing staff has been shown to improve service delivery and patient care (Smith \& Topping 2001).

Triage plays a vital role in our health care system, as it enables undifferentiated patients, within a dynamic environment, to be managed in a timely manner based on clinical urgency (Hodge et al. 2013). As triage requires complex decisions in timecritical environments, triage should be undertaken by experienced nurses who have been specifically trained to perform this role (Ministry of Health NSW 2013). McCallum Pardey (2007) explored the varying roles and skills of triage nurses, including critical thinking and decision-making, conducting rapid clinical assessments, assessing urgency and severity in unpredictable situations while ensuring positive patient outcomes and providing a high standard of care.

Registered Nurses who perform emergency triage require specific educational training that is delivered as part of the standardised national training course endorsed by the College of Emergency Nurses Australasia (CENA 2009). The Emergency Triage Education Kit (ETEK) is a resource for nurse educators that seeks to provide overall triage education for ED nurses with an emphasis on triage consistency when using the Australasian Triage Scale (ATS) (CENA 2009; Department of Health 2009). The ATS is a five-tier validated and reliable triage tool that recommends maximum ED waiting times and is used throughout Australian EDs and endorsed by the Australasian College of Emergency Medicine (ACEM 2013) and the CENA (2012). Such training may be provided by clinical nurse educators (ACEM 2012; Northern NSW Local Health District 2015).

Continuing professional development and ongoing support is required to effectively support the competence of ED triage staff (Holloway, Arcus \& Orsborn 2018). Varndell, Hodge and Fry (2019) highlighted how variability in triage education may contribute to poor patient outcomes and emphasised the need for the ongoing revision of ED triage nurse education. To date, very few studies have sought to describe the educational needs of triage nurses. The present study aimed to identify the type of educational support nurses feel they need to manage the triage process.

\section{METHODS}

\section{STUDY DESIGN}

A cross-sectional study used a validated questionnaire to identify the educational support nurses feel they need to manage the triage process.

\section{SETTING}

ED triage nurses currently employed at a NSW regional referral hospital, at which approximately 50,000 patients per year currently present to the ED, were invited to participate in the study. The hospital is a Level 5 hospital with a current bed capacity 
of 247. At the time of the study, 90 registered nurses were working in the ED of the hospital. Of these, 60 were performing a triage role.

Advertisements for the study were posted on the ED news board in the tea room and in various other strategic areas, outlining the purpose of the study and providing the name of an individual to contact for further information. Additional information summarising the key objectives of the study was presented at the regular ED nurses' education sessions during the six-week research period by a research officer and the ED Clinical Nurse Educator. Staff were provided with a Participant Information Statement and had the opportunity to complete a questionnaire at the end of the review meetings or at a time convenient to them. A secure box was located in the ED triage area for the return of completed questionnaires. All responses to the questionnaires were anonymous and the participants were advised that completion of the questionnaire was not compulsory. Only triage trained nurses working in the ED were invited to participate in the study. It was anticipated that approximately $50 \mathrm{ED}$ triage nurses would be available to participate in the study.

\section{ETHICAL CONSIDERATIONS}

This study received ethics approval from the North Coast NSW Human Ethics Committee (Reference No. 2018/ETH00169-11/07/2018).

\section{MEASUREMENT TOOL}

An adapted version of the Hennessy-Hicks Assessment of Training Needs Questionnaire (see Table 1) (Hicks et al. 1996), a psychometrically validated and reliable tool, was used to identify the educational support nurses feel they need to manage the triage process.

Table 1. Adapted Hennessy-Hicks assessment of the training needs questionnaire (Hicks et al. 1996).

\section{Standard Questionnaire}

Adaption Questionnaire

1. Establishing a relationship with patients Establishing a relationship with patients

2. Completing paperwork and/or inputting Completing paperwork and/or inputting routine data routine data

3. Appraising your own performance Appraising your own triage performance

4. Getting along with your colleagues Getting along with your colleagues

5. Communicating with patients face to face Communicating with patients face to face

6. Treating patients Triaging patients using rapid assessment

7. Introducing new ideas at work Introducing new ideas at triage to increase efficiency

8. Accessing relevant literature for your clinical work

Accessing relevant literature for your clinical work 
Standard Questionnaire

Adaption Questionnaire

9. Providing feedback to colleagues

9.

10. Providing information to patients and/or carers

Providing feedback to colleagues about triage decisions

Providing information to patients and/or carers

11. Showing colleagues and/or students how Showing colleagues and/or students how to do things to triage

12. Planning and organising an individual patient's care

Prioritising patient care according to the ATS

13. Evaluating patients' psychological and social needs

Evaluating patients' psychological and social needs

14. Organising your own time effectively Organising your own time effectively

15. Using technical equipment, including computers

Using technical equipment, including computers

16. Undertaking health promotion studies

Understanding, and the escalation of, current public health priorities (e.g., influenza and gastroenteritis)

17. Making do with limited resources

Making do with limited resources

18. Assessing patients' clinical needs

Assessing patients' clinical needs who present to the ED requiring rapid triage assessment and streaming patients to an Early Treatment Zone

19. Working as a member of a team

Working as a member of a team

20. Undertaking administrative activities

Undertaking logistical triage activities, such as patient flow through the ED and the use of the Early Treatment Zone

21. Personally coping with changes in the health service

Personally coping with changes to the triage process in the health service

The questionnaire has previously been used to identify the training needs of health professionals, including nurses, to support the development of appropriate education programs, current practices and models of care (Carlisle, Bhanugopan \& Fish 2011; Hicks \& Hennessy 2011; Holloway et al. 2018). The questionnaire comprised five categories: research/audit, communication/teamwork, clinical tasks, administration and management/supervisory tasks. Participants were asked to use a 7-point Likert scale to rate the categories according to their importance in relation to their role (an assessment of occupation profile [Rating A]) and how well the task was currently being 
performed (an assessment of current skill level [Rating B]). When compared, the two ratings provided a measure of the skill deficit, such that the more important a task is rated and the more poorly it is performed, the greater the need for training.

Training needs were measured as the difference between activity importance and performance scores using a modified version of the valid and reliable Hennessey-Hicks Training Needs Questionnaire (Hennessy \& Hicks 2011; Hicks et al. 1996). This instrument is considered psychometrically robust to modifications of up to $25 \%$ of the tool (Hennessy \& Hicks 2011). The original tool comprised 30 items of which eight can be replaced or amended to customise the instrument for a specific purpose without compromising its validity and reliability (Hennessy \& Hicks 2011). Nine items of the original 30-item instrument that referred to conducting and applying research in the work role were deleted (i.e., items 3, 6, 7, 9,17, 21, 25, 26 and 28, which related to the research/audit sub-section; see Hennessy \& Hicks 2011, pp. 12-13). Minor changes in wording were made to seven items (i.e., Items 3, 6, 7, 9, 11, 18 and 21) in the questionnaire to improve their applicability to the role of triage nurses. As Table 1 shows, permission from the authors was granted to use the tool with the omission of the research category (nine items).

The following three items were modified more significantly:

- Item 12. Prioritising patient care according to the ATS: this item was originally less focused on care prioritisation and more on the individual's care plan ('Planning and organising an individual patient's care');

- Item 16. Understanding, and the escalation of, current public health priorities (e.g., influenza and gastroenteritis). This item was originally more focused on studying rather than responding to public health priorities ('Undertaking health promotion studies'); and

- Item 20. Undertaking triage logistical activities, such as patient flow through the department and the use of the Early Treatment Zone. This item originally referred to administrative tasks generally ('Undertaking administrative activities').

Following the amendments to the questionnaire, the final four categories remained: Communication/Teamwork (Items 1, 4, 5, 9, 10 and 19); Clinical Tasks (Items 6, 8, 12, 13, 16 and 18); and Administration (Items 2, 15 and 20); Management/Supervisory Tasks (Items 3, 7, 11, 14, 17 and 21). An open-response field following the questions was added to allow participants to specify any areas in their job for which they would like to receive further training or instruction. These amendments were overseen by a group of senior ED nurses with education expertise and discussed until a consensus was reached. The nurses in this group were excluded from participating in the study. The adapted Hennessey-Hicks questionnaire was piloted with a small group of senior nurses. No changes were required. The questionnaire took approximately 15 minutes to complete.

\section{ANALYSIS}

Quantitative data analyses were conducted in IBM SPSS version 24 (IBM Corp 2016) by an independent researcher. The distributions of individual items and the category summary scores were calculated. Training needs were determined by the difference in ratings between participants' perceptions of the importance of a work performance task and participants' self-appraisals of their current performance of this task; larger positive differences indicated greater training needs. Similar to Holloway, Arcus and Orsborn(2018), to gain further insight into participants' training needs, responses to the open-response section were clustered into themes using the categories from the Hennessey-Hicks questionnaire (Hennessey \& Hicks 2011). Two researchers 
independently reviewed the qualitative data to identify recurring themes according to the questionnaire categories and then consolidated ideas until a consensus was reached.

\section{RESULTS}

Of the 50 ED triage nurses who were eligible, available and invited to participate in the study, 27 submitted completed questionnaires. This represents a response rate of 54\%. Table 2 summarises the participants' characteristics. On average, participants had 11.33 years of experience in their current role (SD $=7.27$, range $1-30$ years), 15.43 in emergency $(S D=9.80$, range $3.5-48$ years) 13.44 in triage $(S D=9.16$, range $1-40$ years).

Table 2. Participant characteristics.

Participant Characteristics

Mean (SD), Range
years

Average number of years in current position $(n=26) \quad 11.33(7.27), 1-30$

Years of experience in current role $(n=26)$

Less than five

Five to 10

More than 10

$12(46.2)$

Average number of years of experience in emergency 15.43 (9.8),3.5-48

$(n=27)$

Years of experience in emergency $(n=27)$

Less than five

Five to 10

More than 10

$16(59.3)$

Average number of years of triage experience $13.44(9.16), 1-40$

$(n=26)$

Years of experience in triage $(n=26)$

Less than five

$6(23.1)$ 


\section{Participant Characteristics}

Mean (SD), Range ${ }_{\text {Number }(\%)}$
years

Five to 10

More than 10

\section{TRIAGE NURSES' ANALYSIS OF TRAINING NEEDS}

Table 3 sets out triage nurses' training needs. The training needs are ranked in order from highest to lowest. The mean training need identified was the difference between importance and performance (each scored from 1 to 7 ) and thus had a possible range of -6 to +6 . A larger positive score indicated a greater training need. The three top training needs identified by the nurses were:

- Introducing new ideas at triage to increase efficiency;

- Understanding and the escalation of current public health priorities (e.g., influenza and gastroenteritis); and

- Accessing literature relevant to clinical work.

Table 3 presents the importance of training needs as rated by the triage nurses. Activities were ranked broadly by participants with average scores ranging between 0.44 (completing paperwork and/or inputting routine data) and 1.00 (introducing new ideas at triage to increase efficiency).

Table 3. The training needs of triage nurse (ranked from highest to lowest) $(n=27)$.

\begin{tabular}{|c|c|c|c|c|}
\hline $\begin{array}{l}\text { Item } \\
\text { no. }\end{array}$ & Triage nurse work tasks & $\begin{array}{l}\text { Mean } \\
\text { Training } \\
\text { (SD) }\end{array}$ & $\begin{array}{l}\text { Mean } \\
\text { ed*Importance } \\
\text { rating (SD) }\end{array}$ & $\begin{array}{l}\text { Mean } \\
\text { Performance } \\
\text { rating (SD) }\end{array}$ \\
\hline 7 & \multicolumn{2}{|c|}{$\begin{array}{l}\text { Introducing new ideas at triage } 1.00(1.64) \\
\text { to increase efficiency }\end{array}$} & $5.93(1.07)$ & $4.93(1.73)$ \\
\hline 16 & \multicolumn{2}{|c|}{$\begin{array}{l}\text { Understanding, and the } 0.96(1.16) \\
\text { escalation of, current public } \\
\text { health priorities (e.g., influenza } \\
\text { and gastroenteritis) }\end{array}$} & $6.30(0.76)$ & $5.33(1.39)$ \\
\hline 8 & $\begin{array}{l}\text { Accessing relevant literature for } \\
\text { your clinical work }\end{array}$ & $0.63(0.97)$ & $5.85(1.01)$ & $5.19(1.13)$ \\
\hline 9 & $\begin{array}{ll}\text { Providing } & \text { feedback } \\
\text { colleagues } & \text { about tria } \\
\text { decisions } & \end{array}$ & $0.56(1.45)$ & $5.67(1.27)$ & $5.11(1.55)$ \\
\hline 14 & $\begin{array}{l}\text { Organising your own tir } \\
\text { effectively }\end{array}$ & $0.52(0.80)$ & $6.63(0.63)$ & $6.11(0.85)$ \\
\hline
\end{tabular}




\begin{tabular}{|c|c|c|c|c|}
\hline \multicolumn{2}{|c|}{$\begin{array}{l}\text { Item Triage nurse work tasks } \\
\text { no. }\end{array}$} & $\begin{array}{l}\text { Mean } \\
\text { Training } \\
\text { (SD) }\end{array}$ & \multirow{2}{*}{$\begin{array}{l}\text { Mean } \\
\text { ed*Importance } \\
\text { rating (SD) } \\
5.78(1.63)\end{array}$} & \multirow{2}{*}{$\begin{array}{l}\text { Mean } \\
\text { Performance } \\
\text { rating (SD) } \\
\qquad 5.41(1.60)\end{array}$} \\
\hline 11 & $\begin{array}{l}\text { Showing colleagues and/or } \\
\text { students how to triage }\end{array}$ & $0.37(1.78)$ & & \\
\hline 18 & $\begin{array}{l}\text { Assessing patients' clinical } \\
\text { needs who present to the ED } \\
\text { requiring rapid triage } \\
\text { assessment and streaming } \\
\text { patients to appropriate treatment } \\
\text { areas }\end{array}$ & $0.33(0.55)$ & $6.63(0.88)$ & $6.30(0.95)$ \\
\hline 20 & $\begin{array}{l}\text { Undertaking logistical triage } \\
\text { activities, such as patient flow } \\
\text { through the ED and the use of } \\
\text { the Early Treatment Zone }\end{array}$ & $0.33(0.92)$ & $6.64(0.64)$ & $6.28(0.79)$ \\
\hline 19 & Working as a member of a team & $0.26(0.66)$ & $6.63(0.88)$ & $6.37(0.79)$ \\
\hline 5 & $\begin{array}{l}\text { Communicating with patients } \\
\text { face to face }\end{array}$ & $0.22(0.70)$ & $6.74(0.66)$ & $6.52(0.80)$ \\
\hline 6 & $\begin{array}{l}\text { Triaging patients using rapid } \\
\text { assessment }\end{array}$ & $0.22(0.64)$ & $6.30(0.76)$ & $6.07(1.04)$ \\
\hline 13 & $\begin{array}{l}\text { Evaluating patients' } \\
\text { psychological and social needs }\end{array}$ & $0.22(0.97)$ & $5.59(1.25)$ & $5.37(1.50)$ \\
\hline 15 & $\begin{array}{l}\text { Using technical equipment, } \\
\text { including computers }\end{array}$ & $0.22(1.25)$ & $6.12(1.11)$ & $5.88(1.02)$ \\
\hline 12 & $\begin{array}{l}\text { Prioritising patient care } \\
\text { according to the ATS }\end{array}$ & $0.19(0.56)$ & $6.81(0.56)$ & $6.63(0.69)$ \\
\hline 21 & $\begin{array}{l}\text { Personally coping with changes } \\
\text { to the triage process in the } \\
\text { health service }\end{array}$ & $0.19(1.00)$ & $6.21(1.06)$ & $6.00(0.83)$ \\
\hline 10 & $\begin{array}{l}\text { Providing information to patients } \\
\text { and/or carers }\end{array}$ & $0.15(1.10)$ & $6.11(1.05)$ & $5.96(1.13)$ \\
\hline $3 \#$ & $\begin{array}{l}\text { Appraising your own triage } \\
\text { performance\# }\end{array}$ & $0.04(1.40)$ & $5.96(1.19)$ & $5.88(1.11)$ \\
\hline 17 & Making do with limited resources & $-0.04(1.29)$ & $5.59(1.74)$ & $5.63(1.39)$ \\
\hline 4 & $\begin{array}{l}\text { Getting along with your } \\
\text { colleagues }\end{array}$ & $-0.15(1.23)$ & $5.89(1.25)$ & $6.04(1.13)$ \\
\hline
\end{tabular}




\begin{tabular}{llrr}
$\begin{array}{l}\text { Item Triage nurse work tasks } \\
\text { no. }\end{array}$ & $\begin{array}{l}\text { Mean } \\
\text { Training } \\
\text { (SD) }\end{array}$ & $\begin{array}{c}\text { Mean } \\
\text { need*Importance } \\
\text { rating (SD) }\end{array}$ & $\begin{array}{l}\text { Mean } \\
\text { Performance } \\
\text { rating (SD) }\end{array}$ \\
\hline $1 \quad \begin{array}{l}\text { Establishing a relationship with } \\
\text { patients }\end{array}$ & $-0.30(1.46)$ & $5.48(1.48)$ & $5.78(1.09)$ \\
\hline$\quad \begin{array}{l}\text { Completing paperwork and/or } \\
\text { inputting routine data }\end{array}$ & $-0.44(1.34)$ & $5.30(1.35)$ & $5.74(1.02)$ \\
\hline
\end{tabular}

Note. *'Training need' was calculated by subtracting the 'mean rating of a current performance in a task' from the 'mean importance rating of a task'. Ratings for importance and performance ranged from 1 (not well) to 7 (very well). \#Task 3 had $n=26$ participants

Table 3 also shows the importance of work performance tasks as rated by triage nurses. All of the activities were ranked as strongly important by participants with average scores ranging between 5.30 (completing paperwork work and/or inputting routine data) and 6.81 (prioritising patient care according to the ATS).

Table 3 also presents the level of performance of the skilled tasks as rated by triage nurses. The level of performance for all activities were ranked highly; however, the range was broad; average scores ranged from 4.93 (introducing new ideas at triage to increase efficiency) to 6.63 (prioritising patient care according to the ATS).

\section{OVERALL TRAINING NEEDS BASED ON QUESTIONNAIRE CATEGORIES}

The most important overall training need fell in the category of Clinical Tasks (Items 16, 8 and 18), followed by Management/Supervisory Tasks (Items 7, 14 and 11), Communication/Teamwork (Items 19, 5 and 10) and Administration (Item 20) (see Table 4).

Table 4. Training needs based on categories.

Domain

Clinical Tasks

Management/Supervisory Tasks

Communication/Teamwork

Administration

\section{OPEN-ENDED RESPONSES}

An open-response field following the questions allowed participants to specify any areas of their job for which they would like to receive further training or instruction. Open-ended responses $(n=53)$ were received from 18 participants. The responses were clustered into themes using the categories from the Hennessey-Hicks 
questionnaire (see Figure 1). The largest area of training needs fell in the clinical task category ( 25 or $47 \%$ ). Of these, the largest response related to vital signs ( 11 or $44 \%$ ). Other themes included consistency of triaging according to the ATS (4 or 16\%), physical assessments, such as fracture care, eye and stroke assessments (3 or 12\%), rapid triage assessment processes ( 2 or $8 \%$ ), ED models of care ( 2 or $8 \%$ ) and other ( 3 or $12 \%$ ).

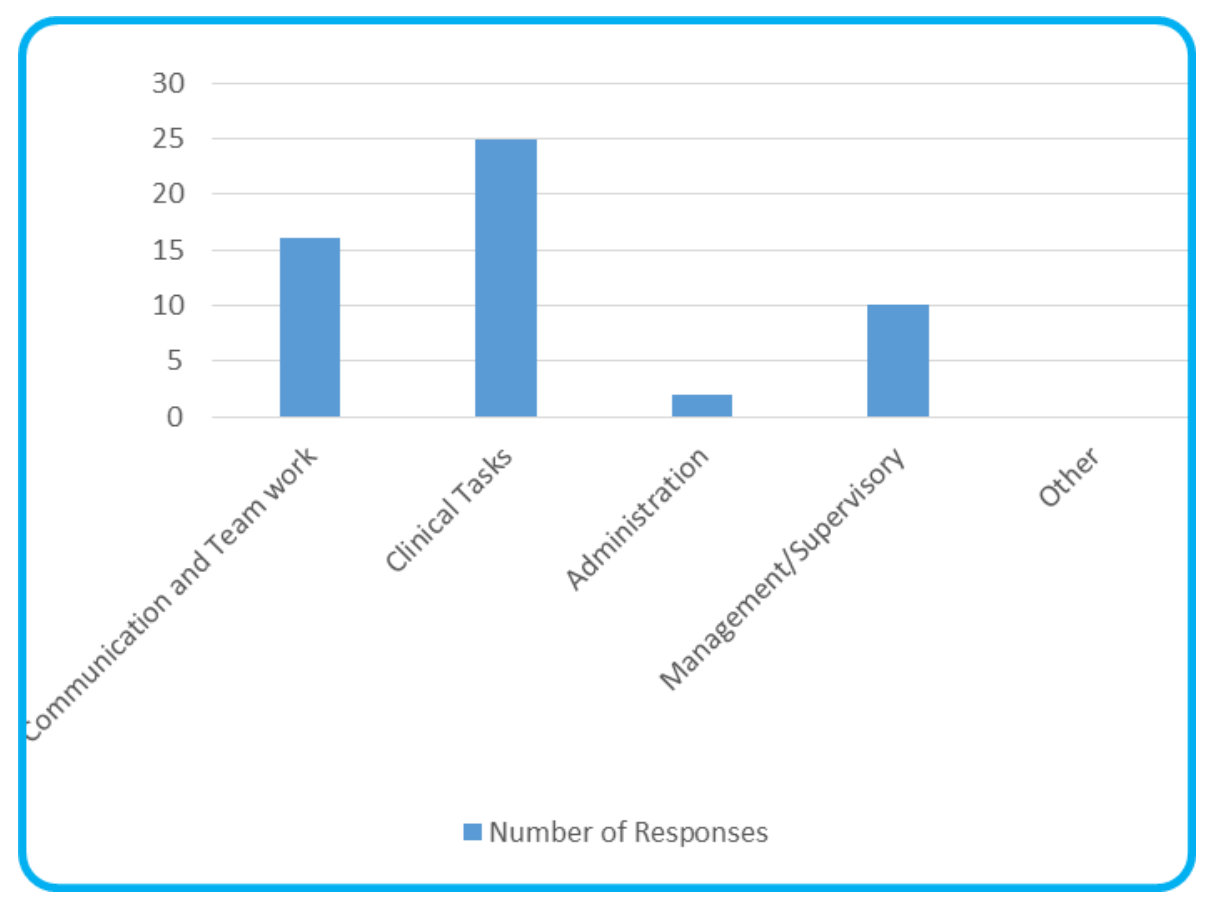

Figure 1. Training needs based on Hennessy-Hicks's categories: Responses to open-ended questions.

\section{DISCUSSION}

The Hennessey-Hicks Training Needs Analysis Questionnaire was adapted for this study (Hennessey \& Hicks 2011). A training needs gap was identified by calculating the difference in mean rating scores between the importance of a work performance task and participant nurses' self-appraisal of their current performance of that task. The findings of this study showed that triage nurses ranked the importance and performance of all tasks highly. The top three larger positive differences indicated that to manage the triage process, nurses were of the view that they required educational support in relation to introducing new ideas to increase efficiency, current public health priorities and accessing the relevant literature. Similar to Holloway et al. (2018), the clinical tasks category was identified by triage nurses as a priority area for which there was an overall training need. Notably, the triages nurses identified training in vital signs and physical assessment as priority areas.

Efficient triage processes are critical to provide safe and best quality care to patients accessing EDs (Burgess et al. 2019; Hitchcock et al. 2014). Recently, the ACEM (2016) stated that triage should be an assessment of the presenting problem and general appearance, including physiological observations whereby vital signs may be required to estimate urgency if time permits (Burgess et al. 2019). Part of the revised process 
includes limiting the responsibilities and tasks of triage nurses and focusing on a brief clinical assessment to ensure urgency and timely clinical care (MoH 2013; ACEM 2016). This change aligns with the literature that discusses limiting the traditional responsibilities of triage nurses, such as assessing vital signs, to avoid queuing and delays at triage (ACEM 2016; $\mathrm{MoH}$ 2013; Burgess et al. 2019). These recent changes to the ACEM's (2016) position on triage may explain why nurses were of the view that they needed training in the areas of introducing new ideas to increase efficiency and clinical tasks with a strong emphasis on vital signs. Further education to support ED nurses to triage efficiently using brief clinical assessments may be required.

As evidenced by Holloway et al. (2018), the participants in this study indicated that they required training in relation to understanding, and the escalation of, current public health priorities and accessing relevant literature to manage the triage process. Holloway et al (2018) suggested that primary health care and health promotion reflects a gap in confidence in the provision of evidenced-based care. Triage education largely supports complex technical skills and accuracy to determine the primary issue requiring immediate treatment (Innes, Plummer \& Considine 2011). Recent variations to triage nursing roles places an emphasis on both the theoretical and practical aspects of nursing to cope with the demands of the role (Sanders \& Minick 2014). Education in health promotion and the development of skills to access the relevant literature will support the complexity of the nurses' role and increase their confidence and competence in their ability to manage the triage process.

\section{LIMITATIONS}

As this study was restricted to a single site and comprised only a small sample size of triage nurses, the generalisability of the results may be limited.

\section{CONCLUSION}

Triage nurses have an autonomous role that requires complex critical thinking in the context of emergency care, patient safety and outcomes (CENA 2012; McCallum Pardey 2007; Varndell et al. 2019). Triage nurses receive education as part of the standardised national training course; however, the nurses in this study indicated a need for further training and support (Department of Health 2009). The results of this study will inform the design of future education programs and the development of the capability of the nursing workforce to triage efficiently and effectively.

\section{Acknowledgements}

The authors would like to acknowledge:

- Supervisors Kerith Duncanson and David Schmidt of the Rural Research Capacity Building Program (RRCBP) at the Health Education Training Institute(HETI);

- Shirley Walker, Whole of Health Manager;

- Theresa Caruana, Research Officer; and

- Dr Rob Davies, Director or Emergency Medicine and ED colleagues.

\section{Conflict of Interest}

The authors declare no conflict of interest. 
This project was funded by HETI's Rural Research Capacity Building Program.

\section{REFERENCES}

Australasian College of Emergency Medicine (ACEM) 2012, Statement on the delineation of emergency departments. West Melbourne, viewed 9 October 2019, https://acem.org.au/getmedia/aa6c120d-bd9f-4850-a257-

2b9a8f3860b3/S12_Statement_on_the_Delineation_EDs_Nov-12_v05-(1).aspx

Australasian College of Emergency Medicine (ACEM) 2013, Policy on the Australasian triage scale, ACEM, West Melbourne, viewed 9 October 2019, https://acem.org.au/getmedia/484b39f1-7c99-427b-b46e-005b0cd6ac64/P06Policy-on-the-ATS-Jul-13-v04.aspx

Australasian College of Emergency Medicine 2016, Guidelines on the implementation of the Australasian triage scale in emergency departments, ACEM, West Melbourne, viewed 9 October 2019, https://acem.org.au/getmedia/51dc74f79ffo-42ce-872a-

437f3db640a/G24 04 Guidelines on Implementation of ATS Jul-16.aspx

Burgess, L, Kynoch, K \& Hines, S 2019, 'Implementing best practice into the emergency department triage process', International Journal of Evidence-Based Healthcare, vol. 17 , no. 1 , pp. 27-35.

Carlisle, J, Bhanugopan, R \& Fish, A 2011, 'Training needs of nurses in public hospitals in Australia: review of current practices and future research agenda', Journal of European Industrial Training, vol. 35, no. 7, pp. 687-701.

College of Emergency Nursing Australasia (CENA) 2009, Position statement-triage nurse, CENA, Hobart, viewed 9 October 2019, https://www.cena.org.au/wpcontent/uploads/2014/10/CENA Position Statement Triage Nurse.pdf

College of Emergency Nursing Australasia (CENA) 2012, Position statement-triage and the Australasian triage scale, CENA, Hobart, viewed 9 October 2019, https://www.cena.org.au/wp-content/uploads/2014/10/2012_06_14_CENA__Position_Statement_Triage.pdf

Department of Health 2009, Emergency triage education kit, Commonwealth of Australia, Canberra, viewed 9 October 2019, https://www1.health.gov.au/internet/main/publishing.nsf/Content/casemix-EDTriage\%20Review\%20Fact\%20Sheet\%20Documents

Gould, D, Kelly, D, White, I \& Chidgey, J 2004, 'Training needs analysis. A literature review and reappraisal', International Journal of Nursing Studies, vol. 41, no. 5, pp. 471-486.

Hicks, C \& Hennessy, D 2011, Hennessy-Hicks Training needs analysis questionnaire and manual, University of Birmingham, Birmingham UK, viewed 9 October 2019, https://www.who.int/workforcealliance/knowledge/toolkit/19/en/

Hicks, C, Hennessy, D, Cooper, J \& Barwell, F 1996, 'Investigating attitudes to research in primary health care teams', Journal of Advanced Nursing, vol. 24, no. 5, pp. 1033-1041. 
Hitchcock, M, Gillespie, B, Crilly, J \& Chaboyer, W 2014, 'Triage: an investigation of the process and potential vulnerabilities', Journal of Advanced Nursing, vol. 70, no. 7, pp. 1532-1541.

Hodge, A, Hugman, A, Varndell, W \& Howes, K 2013, 'A review of the quality assurance processes for the Australasian triage scale (ATS) and implications for future practice', Australasian Emergency Nursing Journal, vol. 16, no. 1, pp. 21-29.

Holloway, K, Arcus, K \& Orsborn, G 2018, 'Training needs analysis - the essential first step for continuing professional development design', Nurse Education in Practice, vol. 28, pp. 7-12.

IBM Corp 2016, IBM SPSS Statistics for Windows, version 24, IBM Corp, Armonk NY.

Innes, K, Plummer, V \& Considine J 2011, 'Nurses' perceptions of their preparation for triage', Australasian Emergency Nursing Journal, vol. 14, no. 2, pp. 81-86.

McCallum Pardey, TG 2007, 'Emergency triage', Australasian Emergency Care, vol. 10, no. 2, pp. 43-45.

Ministry of Health NSW (MoH) 2013, Triage of patients in NSW emergency departments, PD2013_047, MoH, Sydney, viewed 9 October 2019, https://intranet.nnswlhd.health.nsw.gov.au/docs/PD2013_047-triage-ofpatients-in-nsw-emergency-departments-v-001.pdf

Northern NSW Local Health District 2015, Triage of patients presenting to emergency departments within Northern NSW Local Health District, NC-NNSW-POL-6519-12, viewed 9 October 2019, https://intranet.nnswlhd.health.nsw.gov.au/docs/NCNNSW-POL-6519-12-triage-of-patients-presenting-to-emergency-departmentswith-nnsw-lhd-v-001.pdf

Sanders, S, \& Minick, P 2014, Making better decisions during triage. Emergency Nurse, $\begin{array}{llll}\text { vol. } 22, & \text { no. } & 6, & \end{array}$ doi:http://dx.doi.org.ezproxy.scu.edu.au/10.7748/en.22.6.14.e1336

Smith, J \& Topping, A 2001, “Unpacking the "value added" impact of continuing professional education: a multi-method case study approach' Nursing Education Today, vol. 21, pp. 341-349.

Varndell, W, Hodge, A \& Fry, M 2019, 'Triage in Australian emergency departments: results of a New South Wales survey', Australasian Emergency Care, vol. 22, no. 2, pp. 81-86. 